\title{
Reports
}

\section{Considerations for conducting global health research with adolescents in rural communities}

\author{
Tom D Ngabirano', Melissa A Saftner ${ }^{2}$, Annie-Laurie McRee ${ }^{3}$, Barbara J McMorris ${ }^{2}$ \\ 1 Department of Nursing, Makerere University, Kampala Uganda, 2 Department of Nursing, University of Minnesota, Twin Cities, Minnesota, United \\ States, ${ }^{3}$ Department of Pediatrics, University of Minnesota, Twin Cities, Minnesota, United States \\ Keywords: global health, rural communities, adolescents
}

https://doi.org/10.29392/001c.17605

\section{Journal of Global Health Reports}

Vol. 4, 2020

Adolescence is a rapid developmental period that requires attention to biology and psychosocial milestones; it is characterized by youth exploration of external environments outside of the family context. The estimated1.8 billion adolescents (ages 10-24 years) globally comprise 25\% of the world's population, $90 \%$ of whom live in low- or middle-income countries. ${ }^{1}$ Uganda has one of the youngest populations in the world, with 1 in 3 Ugandans classified as an adolescent, and an expected overall increase in these numbers by 2040.1,2

Like other countries, Uganda varies regionally with regard to urban and rural contexts. Most research studies have been conducted in more accessible areas in the East and Central regions of the country. Little information exists regarding best practices for conducting research among adolescents in more remote areas-such as rural fishing villages-despite high rates of health risk behaviors such as transactional sex, alcohol and substance use. ${ }^{3,4}$ Although all children and adolescents are considered vulnerable research populations, youth from rural Ugandan fishing communities are particularly marginalized due to high unemployment rates for community members, disparate access to education services, and high illiteracy rates among both parents and adolescents, ${ }^{5}$ making it even more important to develop systems to fairly recruit participants, collect data, and ensure youth feel comfortable in their decision to participate in research.

Drawing on our multicultural (from Uganda and the United States), interdisciplinary (representing the disciplines of public health, nursing and sociology) team's experience conducting research about adolescent risk behaviors and health promotion activities in four Ugandan fishing villages in 2017, this paper has two goals: (i) to reflect on key areas for consideration for conducting global health research with adolescents in rural communities; and (ii) to describe lessons learned to enhance youth autonomy and minimize coercion. The study was conducted in four villages located within Queen Elizabeth National Park with shorelines on Lake Edward or Lake George in the southwestern part of Uganda. Additional information regarding the study settings has been reported elsewhere Ngabirano et al. (in press). Study procedures and key study findings from this exemplar project are described elsewhere. ${ }^{6}$ Institutional review board approval was obtained from the University of Minnesota, Makerere University School of Health Sciences Research and Ethics committee, and the Uganda
National Council of Science and Technology.

\section{CONSIDERATIONS FOR RESEARCH}

Enhancing village mobilizer participation. Although recruitment processes are challenging for all research projects, researchers working internationally often encounter additional barriers. To overcome challenges related to recruitment and community engagement, village mobilizers (VMs) become critical members of research teams. VMs work under the guidance of the research team to support multiple facets of recruitment, data collection, intervention implementation and on-site coordination of resources. VMs often live in the community and are known and respected by the local population. Although there are advantages to having community members support recruitment, there is also the potential for selection bias as we experienced in our research study.

We identified two VMs, one male and one female, from each of four villages prior to recruitment. Selection of VMs was based on prior participation in health-related research, living in the same community and prior experience as a village Health team member. The VMs were provided with information regarding the purpose of the study and the inclusion criteria. Before the research team arrived in a village, VMs informed community members about the upcoming research project and opportunities for their children to participate. In village one, the research team arrived and were greeted by the VMs who had pre-selected the adolescents to participate in the study. After completing the study survey with the first ten participants, it became clear to the team that one VM in particular had chosen those village members who he/she believed best reflected the values of the community. During a break, the team spoke with the VMs and learned that they had chosen "good kids" for the study. Specifically, the majority of young participants were from the same section of the village, and the mobilizers had intentionally selected households aligned to their faith.

Once this potential for selection bias was identified, the research team developed a method to counteract the bias in villages two, three and four. Upon arrival in subsequent villages, VMs met with the study investigators and provided a map of all homes in the village. On that map, the VM noted the number of male and female adolescents in each home (Figure 1). Research staff then purposively selected homes 


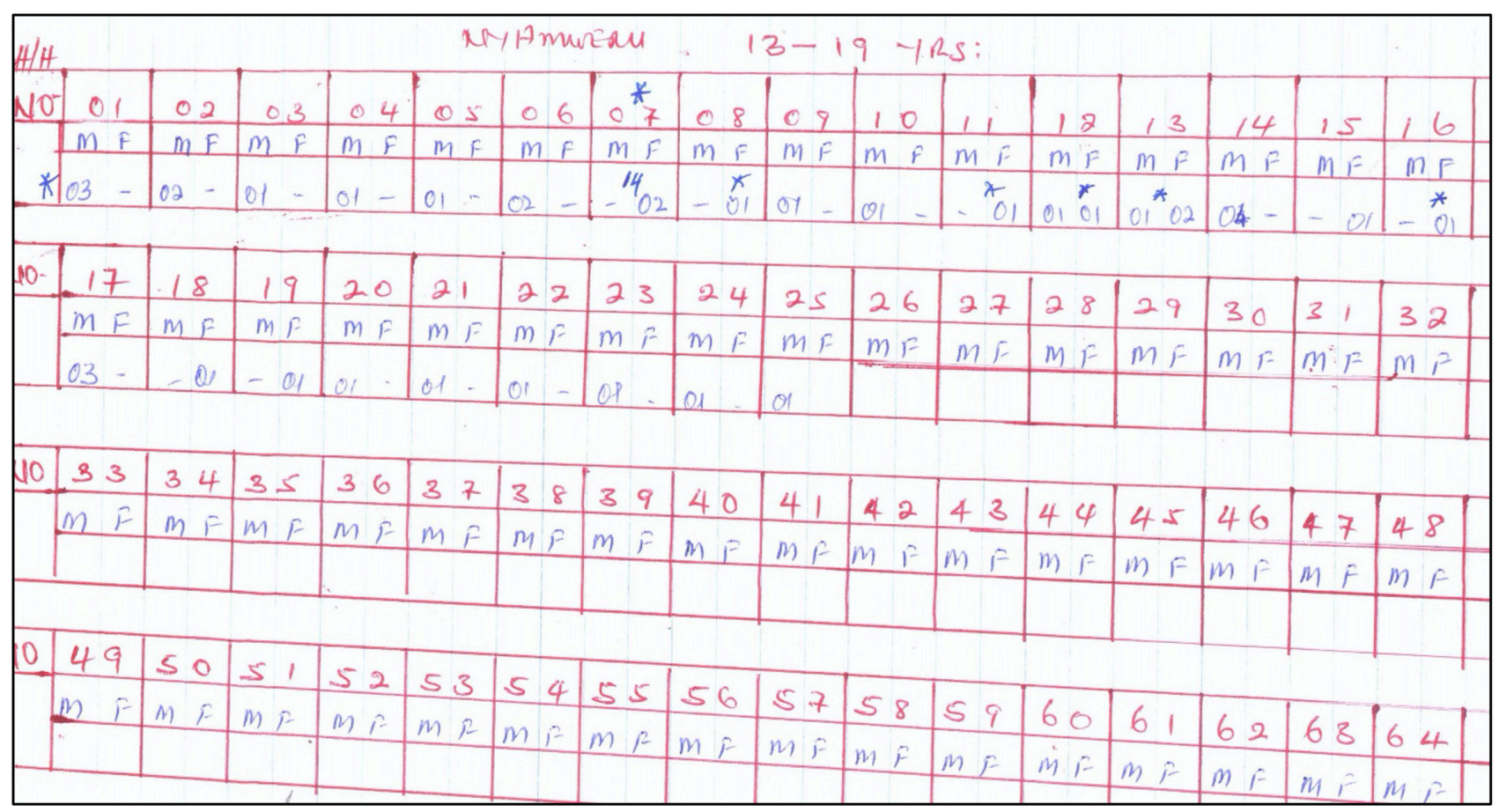

Figure 1. Sample Village Mobilizer Chart

Note. To address potential selection bias in villages 2-4, village mobilizers (VM) provided a chart mapping all homes and the number of resident adolescent children by sex. Study investigators then purposively selected homes to visit to discuss the study.

to visit to discuss the study. The VM then accompanied an investigator to each house (or workplace if the parent was known to be at their place of business). Because the VM had already notified the community about the study, parents and guardians were not surprised by the arrival of non-community members. Collaboration with VMs enhanced data collection and resulted in less homogenous samples from villages two, three and four, likely due to the enhanced work with VMs. ${ }^{6}$

Balancing autonomy for informed consent/assent. Adolescents are considered a vulnerable population for research as they may not understand all the potential risks, benefits and procedures necessary to provide informed consent. ${ }^{7}$ Cultural, social and economic issues also pose challenges to securing meaningful informed consent and assent from adolescent participants. ${ }^{8}$ Thus, it is important to explore ways to ensure that researchers working cross-culturally are promoting the autonomy of vulnerable and marginalized adolescents. This entails recognizing an inherent power dynamic that is created when researchers from Western countries arrive in a community, as well as cultural norms for hierarchy and respect for elders. Further, given the illiteracy rates in Uganda, ${ }^{5}$ particularly in rural areas, it is important to ensure that both literate and non-literate participants understand the voluntary nature of a study. Adolescents' decisions about whether or not to participate in research may be impacted by a parent's presence during the assent process, ${ }^{9}$ making it particularly important that the process is a dynamic one that respects adolescents' autonomy.

We took multiple steps to minimize adolescent vulnerability to coercion including consenting parents of minors at their home or place of work but conducting the assent process at the data collection site. Parental consent at home/work gave the parent or guardian the opportunity to ask questions about the study in a safe environment and minimize the potential for coercion or undue inducement of their children. Research team members provided detailed information about the study and responded to questions and concerns that were raised by parents and guardians. We then asked guardians to provide written consent to allow their children to participate in the study. It is important to note that research team members who went door to door were all native Ugandans, familiar with the village community, and spoke both English and the local language. These team members were present during consent/assent procedures. At the data collection site, adolescents were informed that participation was voluntary and that nonparticipation would not be communicated to either the community mobilizers or their guardians. After research team members confirmed that youth understood the purpose of the study, adolescents assented or consented by signing their name on the IRB approved forms. Those who were unable to write consented by marking the signing position on the consent paper with their fingerprint.

Incentivizing participation ethically. Incentivizing research participation, whether through monetary incentives (e.g., cash, gift cards/certificates) or goods (e.g., items that would be attractive to participants) can be controversial. ${ }^{10}$ There are mixed beliefs regarding incentives; some believe that incentives are generally appropriate while others report concern for coercion of marginalized or underrepresented groups. Although modest financial incentives likely do not cloud the judgment of participants, it is unclear whether parental coercion occurs when a financial incentive is offered to their child, and how the consent and assent 
processes influence autonomous decisions of adults and youth.

Aligned with our goals to respect the autonomy of adolescents and their right to refuse to participate in the study irrespective of parent/guardian consent or familial desire, we provided a gift bag (including a notebook, pens, pencils, washing soap, and a kilogram of sugar that was valued at \$5 USD) to all youth who participated in the consent/assent process, irrespective of whether they participated in the study. This process helped address the inherent social and allocational vulnerabilities. We did not want to penalize youth or create a deferential vulnerability for those who opted not to participate after parental consent was provided, by withholding the gift bag.

\section{LESSONS LEARNED}

From our work in rural Ugandan fishing villages, our team learned a number of lessons which we hope can be useful to others conducting research with adolescents in similar communities.

- Involving community members, such as VMs, can facilitate recruitment, but collaborative partnerships with community members require that both study team and community members understand the intent of the study and support an objective recruitment process.

- Having a cross-cultural team including multi-lingual members who reflect similar cultural values and traditions of the community supports data collection and community engagement.

- Considering adolescents' autonomy is an important precursor to developing procedures for recruitment and retention in research studies.

- Offering an incentive for the consent/assent process that is not participation related allows true informed consent/assent and ensures adolescents who decide not to participate, even with parent consent, are not penalized.

Given the vulnerabilities of working with marginalized adolescents, ensuring that youth are fairly selected for research participation, have the autonomy to assent/consent is critical for ethical global health research. Furthermore, incentives should not be contingent on a youth's full participation in the study to ensure their own personal safety and autonomy are respected.

\section{FUNDING}

None

\section{AUTHORSHIP CONTRIBUTIONS}

All authors contributed equally to the manuscript.

\section{COMPETING INTERESTS}

The authors completed the Unified Competing Interest form at www.icmje.org/coi_disclosure.pdf (available upon request from the corresponding author), and declare no conflicts of interest.

\section{CORRESPONDENCE TO}

Tom D Ngabirano

Department of Nursing,

Makerere University

Kampala, Uganda

tomngabirano@gmail.com

Submitted: August 19, 2020 GMT, Accepted: October 02, 2020 GMT 


\section{REFERENCES}

1. Salam RA, Das JK, Lassi ZS, Bhutta ZA. Adolescent Health and Well-Being: Background and Methodology for Review of Potential Interventions. Journal of Adolescent Health. 2016;59(2):S4-S10. doi:10.1016/i.j adohealth.2016.07.023

2. Uganda Bureau Of Statistics (UBOS) and ICF. The Uganda Demographics and Health Survey 2016: Key Indicators Report. Kampala; 2017.

3. Opio A, Muyonga M, Mulumba N. HIV infection in fishing communities of Lake Victoria Basin of Uganda--a cross-sectional sero-behavioral survey. PLoS One. 2013;8(8):e70770. doi:10.1371/journal.pon e.0070770

4. Kiene SM, Sileo KM, Dove M, Kintu M. Hazardous alcohol consumption and alcohol-related problems are associated with unknown and HIV-positive status in fishing communities in Uganda. AIDS care. 2019;31(4):451-459. doi:10.1080/09540121.2018.1497 135

5. Uganda Bureau of Statistics. The Uganda National Household Survey 2016/17. 2018. https://www.ubos.o rg/wp-content/uploads/publications/03_20182016_UN HS_FINAL_REPORT.pdf.
6. Ngabirano TD, Saftner MA, McMorris BJ. Exploring health behaviors in Ugandan adolescents living in rural fishing communities. Journal of School Nursing.

7. Chu AT, DePrince AP, Weinzierl KM. Children's perception of research participation: Examining trauma exposure and distress. Journal of Empirical Research on Human Research Ethics. 2008;3(1):49-58. doi:10.1525/jer.2008.3.1.49

8. Krogstad DJ, Koita OA, Diallo A, et al. Informed consent in international research: The rationale for different approaches. The American journal of tropical medicine and hygiene. 2010;83(4):743-747. $\underline{\mathrm{d}}$ oi:10.4269/aitmh.2010.10-0014

9. Crane S, Broome ME. Understanding ethical issues of research participation from the perspective of participating children and adolescents: A systematic review. Worldviews on Evidence-Based Nursing. 2017;14(3):200-209. doi:10.1111/wvn.12209

10. Halpern SD. Financial incentives for research participation: Empirical questions, available answers and the burden of further proof. The American Journal of the Medical Sciences. 2011;342(4):290-293. doi:10.1097/maj.0b013e3182297925 